\title{
Knowledge, Perception and Opinion of Health Workers on Bone Marrow Transplantation in Nigeria
}

\author{
Adediran $\mathrm{A}^{1 *}$, Wakama $\mathrm{T}^{2}$, Nwadike $\mathrm{K}^{3}$, Damulak $\mathrm{D}^{4}$, Babadoko $\mathrm{A}^{5}$, \\ Kagu M6, Ocheni S7 and Osunkalu V1 \\ ${ }^{1}$ Department of Haematology and Blood Transfusion, University of Lagos, Nigeria \\ ${ }^{2}$ Department of Haematology and Blood Transfusion, National Hospital, Abuja \\ ${ }^{3}$ Department of Pharmacology and Therapeutics, University of Nigeria, Enugu \\ Campus, Nigeria
}

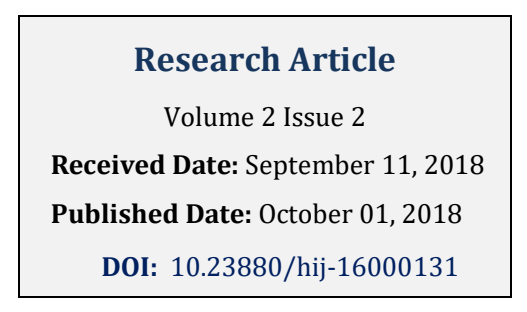

${ }^{4}$ Department of Haematology and Blood Transfusion, Jos University Teaching Hospital, Nigeria

${ }^{5}$ Department of Haematology and Blood Transfusion, Ahmadu Bello University Teaching Hospital, Nigeria

${ }^{6}$ Department of Haematology and Blood Transfusion, University of Maiduguri Teaching Hospital, Nigeria

${ }^{7}$ Department of Haematology and Immunology, University of Nigeria, Nigeria

*Corresponding Author: Adewumi Adediran, Department of Haematology and Blood Transfusion, Faculty of Clinical Sciences, College of Medicine, University of Lagos, Lagos, Nigeria, Tel: +234-802-308-5501; Email: adediranadewumi@yahoo.com

\section{Abstract}

Background: Bone marrow transplantation (BMT) or haematopoietic stem cell transplantation (HSCT) is a procedure used to cure haematopoietic malignancies, poorly functioning haematopoietic or immune system and genetic diseases (eg. sickle cell anaemia). High cost to the patient, poor infrastructure and poor understanding of the procedure by the patients and health care providers limit its acceptance. This study was carried out to determine the opinion, level of knowledge, preparedness and perception of health care personnel on BMT as a baseline for the establishment of a national or regional bone marrow transplant centres in Nigeria.

Materials and Methods: This was a multicentre cross-sectional study amongst health care workers in six tertiary health care centres in Nigeria- Lagos, Abuja, Enugu, Zaria, Maiduguri, and Jos. After obtaining each institution's ethics and research committee approval, a pretested structured questionnaire was administered to respondents aged 18 years and above.

Results: A total of 466 participants including 142 doctors, 123 nurses, 26 pharmacists and pharmacy technicians, 124 laboratory scientists and laboratory technicians and 51 other health care workers such as dieticians, social workers and radiographers participated in the study. About 94.6\% (441 of 466) were aware of BMT. The centre with the highest level of awareness was Abuja (97.6\%). The mean knowledge score of all participants was $38.4 \pm 2.06 \%$. 
Conclusion: Continuous medical education on new innovations and advances in the health sector particularly in BMT is desirable.

Keywords: Haematopoietic malignancies; Immune system; Bone marrow transplantation

Abbreviations: BMT: Bone marrow transplantation; HSCT: Haematopoietic Stem Cell Transplantation; GVHD: Graft-Versus-Host Disease; UBTH: University of Benin Teaching Hospital; SD: Standard Deviation.

\section{Introduction}

Bone marrow transplantation (BMT) or haematopoietic stem cell transplantation (HSCT) is a procedure that involves the infusion of bone marrow cells (haematopoietic stem cells) to reconstitute the haematopoietic system of a patient [1]. The infusion of haematopoietic stem cells generally follows a preparative regimen consisting of agents designed to create marrow space, suppress the patient's immune system, and prevent rejection [1].

This procedure was first developed by Dr. E. Donnall Thomas to treat haematopoietic malignancies in 1963 [2]. $\mathrm{He}$ is recognized as the "father of bone marrow transplantation" and received a Nobel Prize for his pioneering work in 1990 [2]. Approaches currently in use are autologous (using the patient's own haematopoietic stem cells), allogeneic (using related or unrelated donor haematopoietic stem cells) [1,2] and umbilical cord stem cell transplantation.

Clinical applications of BMT include the treatment of haematopoietic malignancies (e.g. Leukaemias, lymphomas, plasma cell neoplasm), replacement or modulation of an absent or poorly functioning haematopoietic or immune system (e.g. Aplastic anaemia) and treatment of genetic diseases (e.g. Sickle cell anaemia and Thalassaemia) in which poor or an insufficient expression of the affected gene product in the patient can be partially or completely overcome by circulating haematopoietic stem cells transplanted from a donor with normal gene expression [3].

The past two decades have witnessed considerable progress in understanding the biology of BMT and in the advancement of supportive care. This has led to a significant reduction in the morbidity and mortality rates associated with this procedure [4]. However, profound and often prolonged pancytopaenia associated with myelosuppressive conditioning; toxicity of the conditioning regimens, graft-versus-host disease (GVHD) and a myriad of opportunistic infections are still major obstacles [4]. With the advent of cord blood stem cell transplantation and the development of less myeloablative conditioning regimens, BMT is beginning to gain wider acceptance and use $[3,4]$.

Apart from the unavailability of matched donors, other reasons that limit acceptance of this procedure in a third world country like Nigeria include the high cost to the patient, poor infrastructure and poor understanding of the procedure by the patients and health care providers.

Nigeria, a developing country with a population of about 196,408,562 [5] with sickle cell anaemia occurring in $2 \%$ of all births [6] and increasing incidence of haematopoietic malignancies and other conditions treatable with BMT, faces the problems of political will, poor infrastructural facilities and lack of sufficient trained personnel as additional obstacles.

Commendable efforts have been made by the University of Benin Teaching Hospital (UBTH), Benin, Nigeria in pioneering the procedure in Nigeria [7]. While other centres are making serious efforts in the training of personnel, and provision of infrastructure through agreement with some centres in developed countries, their commitments are yet to yield meaningful results.

Bone marrow transplantation is a multidisciplinary procedure, which requires the services of many health care personnel such as medical doctors in various specialties, nurses, pharmacists, clinical psychologists, laboratory scientists/technicians, dieticians, radiographers, social health workers/health counsellors etc involved in one way or the other in the management of patients before, during and after the procedure.

These professionals must be well trained in the art and science of this procedure, as it relates to their various disciplines and work in centres equipped with adequate infrastructure to enable them cope with its numerous challenges. 
This study was carried out to determine the level of knowledge, opinion, preparedness and perception of health care personnel in bone marrow transplantation as a baseline for the establishment of a national or regional bone marrow transplantation centres in Nigeria.

\section{Materials and Methods}

This multicentre cross-sectional study amongst health care workers such as Haematologists, Medical Microbiologists, Immunologists, Clinical Pathologists, Anaesthesiologists, Nurses, Pharmacists, Clinical Psychologists, Laboratory Scientists/Technicians, Dieticians, Radiologists/Radiographers, and Social Health Workers/Health Counsellors was carried out in six tertiary health care centres in Nigeria- Lagos, Abuja, Enugu, Zaria, Maiduguri, and Jos.

Consenting participants were recruited consecutively into the study after obtaining each institution's ethics and research committee approval. The questionnaires were given consecutively to health care practitioners who were willing to fill the form. There was no randomisation.

Twenty-five (25) option based questionnaire, pretested for congruency and exclusion of ambiguities, was administered to each participant 18 years and above. Questions 1-7 were on bio-data of each participant; questions 8 and 9 found out if they were aware of BMT and their sources of information; Questions 10-19 tested their knowledge of BMT; Some of the questions asked in this section included "Do you know that BMT can cure some diseases?; if Yes, what diseases can it cure?; What tests should be done to ensure that the donors and recipients are compatible?' Questions 20-25 wanted to know about the respondents' roles in the procedure and the challenges their specialty may face.

\section{Statistical Analysis}

Data were analyzed using SPSS version 20.0 (Statistical Package for Social Sciences, Inc., Chicago, IL, USA). The descriptive data was given as mean \pm standard deviation (SD). The Pearson chi-squared test was used to test for association between discrete variables. A $p$ value was considered to be statistically significant when it is $\leq$ 0.05 .

\section{Results}

A total of 466 participants from six tertiary health centres across Nigeria; 82 participants from Abuja, 144 from Enugu, 42 from Jos, 78 from Lagos, 50 from Maiduguri, and 70 from Zaria participated in the study. The participants included 142 doctors, 123 nurses, 26 pharmacists and pharmacy technicians, 124 laboratory scientists/laboratory technicians and 51 other health care workers such as dieticians, social workers, radiographers etc.

Demographic characteristics of participants are presented in Table 1. The participants consisted of 230 (49.4\%) males and 236 (50.6\%) females. The age range with the highest frequency (41\%) was 28-37 years followed by those aged 38-47 years with a frequency of $28.3 \%$. Subjects within the age range of 18-27 years had the lowest frequency of $14.4 \%$. Ethnicity of the participants was in the following order- Igbo (38.8\%); Yoruba (25.3\%); Hausa/Fulani (5.8\%); Minority (3\%). With a frequency of 78.1\% (364 of 466), majority of participants were Christians. This was followed by Muslims (21.7\%). Only one $(0.2 \%)$ of the participants practised traditional religion. The profession with the highest frequency was medical doctors with a frequency of $30.5 \%$ (142 of 466 ) with pharmacists constituting the least professional enrolees (5.6\%).

\begin{tabular}{|c|c|c|c|c|c|c|}
\hline \multicolumn{2}{|c|}{ Parameters } & \multicolumn{5}{c|}{ Groupings } \\
\hline Age (years) & $18-27$ & $28-37$ & $38-47$ & $>48$ & Total & \\
\hline Frequency (\%) & $67(28.3)$ & $193(41)$ & $132(28)$ & $74(15.9)$ & 466 & \\
\hline Ethnicity & Yoruba & Igbo & Hausa/Fulani & Others & Total & \\
\hline Frequency (\%) & $118(25.3)$ & $181(38.8)$ & $27(5.8)$ & $14(3)$ & 466 & \\
\hline Religion & Christians & Muslims & Traditional & Total & & \\
\hline Frequency (\%) & $364(78.1)$ & $101(21.7)$ & $1(0.2)$ & 466 & & \\
\hline Profession & Doctors & Nurses & Pharm/Techns & Lab sci/Techns & Others & Total \\
\hline Frequency & $142(30.5)$ & $123(26.4)$ & $26(5.6)$ & $124(26.6)$ & $51(10.9)$ & 466 \\
\hline
\end{tabular}

KEY: Pharm- Pharmacists; Scients -Scientists; Techns-Technicians.

Table 1: Demographic Characteristics of Participants. 
Table 2 shows the frequency of awareness and source of information in each centre. About 94.6\% (441 of 466) of females were aware of BMT. The centre with the highest level of awareness was Abuja (97.6\%). This was followed closely by Enugu and Maiduguri centres with frequencies of $96.5 \%$ and $96.0 \%$ respectively. Zaria with the frequency of $88.6 \%$ (62 of 70) had the lowest level of awareness.

\begin{tabular}{|c|c|c|c|c|c|c|c|}
\hline Parameter & Abuja & Enugu & Jos & Lagos & Maiduguri & Zaria & Total \\
\hline $\mathrm{N}$ & 82 & 144 & 42 & 78 & 50 & 70 & 466 \\
\hline Awareness & & & & & & & \\
\hline Yes (\%) & $80(97.6)$ & $139(96.5)$ & $40(95.2)$ & $72(92.3)$ & $48(96.0)$ & $62(88.6)$ & $441(94.6)$ \\
\hline No (\%) & $2(2.4)$ & $5(3.5)$ & $2(4.8)$ & $6(7.7)$ & $2(4.0)$ & $8(11.4)$ & $25(5.4)$ \\
\hline Source of Information & & & & & & & \\
\hline Media (\%) & $32(40)$ & $52((37.4)$ & $12(30)$ & $18(25)$ & $14(29.2)$ & $16(25.8)$ & $144(32.7)$ \\
\hline Discussion (\%) & $16(20)$ & $47(33.8)$ & $9(22.5)$ & $12(16.7)$ & $8(16.7)$ & $12(19.4)$ & $104(23.6)$ \\
\hline School (\%) & $10(12.5)$ & $11(7.2)$ & $9(22.5)$ & $99(12.5)$ & $10(29.2)$ & $10(16.1)$ & $59(13.3)$ \\
\hline Journal (\%) & $8(10)$ & $13(9.4)$ & $5(12.5)$ & $6(8.3)$ & $5(10.4)$ & $5(8.1)$ & $42(9.5)$ \\
\hline Seminar (\%) & $3(3.8)$ & $2(1.4)$ & $0(0)$ & $4(5.6)$ & $3(6.3)$ & $2(3.2)$ & $14(3.2)$ \\
\hline Conferences (\%) & $2(2.5)$ & $0(0)$ & $1(2.5)$ & $1(1.4)$ & $4(8.3)$ & $4(6.5)$ & $12(2.7)$ \\
\hline Others (\%) & $6(17.5)$ & $6(4.3)$ & $3(7.5)$ & $10(13.9)$ & $3(6.3)$ & $8(12.9)$ & $36(8.2)$ \\
\hline No response (\%) & $3(3.8)$ & $8(5.8)$ & $1(2.5)$ & $12(16.7)$ & $1(2.1)$ & $5(8.1)$ & $30(6.8)$ \\
\hline Total & $80(100)$ & $139(100)$ & $40(100)$ & $72(100)$ & $48(100)$ & $62(100)$ & $441(100)$ \\
\hline
\end{tabular}

Table 2: Awareness and sources of Information.

The source of information with the highest percentage (32.7\%) was the media. This was followed by 'discussions with colleagues' (31.7\%). Of those who obtained information from the media, Abuja was highest with a percentage of $40.0 \%$ (32 of 80), followed by Enugu centre (37.4\%) while Lagos centre was the lowest (25\%). Frequencies of obtaining information from other sources such as schools (13.3\%), journals (9.5\%), seminars $(3.2 \%)$ and conferences $(2.7 \%)$ were very low.

About $61.5 \%$ (271 of 441 ) of participants were aware of the role of Health Workers in BMT. Maiduguri centre with $83.3 \%$ (40 of 48) had the highest number of participants who were aware of the role of health workers. This was followed by Jos centre with $75 \%$ (30 of 40 ). Enugu centre with $45.3 \%$ (63 of 139) had the least.

The mean knowledge score of all participants was 38.4 $\pm 2.06 \%$ and the mean knowledge score of each centre is as shown in Table 3 with Zaria having the highest mean knowledge score of $48.1 \%$. This was followed by Jos (45.3\%) and Maiduguri (45.1\%). Enugu with $26.1 \%$ had the lowest mean knowledge score.

\begin{tabular}{|c|c|c|c|c|c|}
\hline Centre & No & Mean score\% & Pass (\%) & Fail (\%) & SD \\
\hline Abuja & 80 & 41.5 & $32(40)$ & $48(60)$ & 2.097 \\
\hline Enugu & 139 & 26.1 & $19(13.7)$ & $120(86.3)$ & 1.468 \\
\hline Jos & 40 & 45.3 & $18(45)$ & $22(55)$ & 1.968 \\
\hline Lagos & 72 & 41.2 & $34(47.2)$ & $38(52.8)$ & 2.153 \\
\hline Maiduguri & 48 & 45.1 & $19(39.6)$ & $29(60.4)$ & 1.953 \\
\hline Zaria & 62 & 48.1 & $32(51.6)$ & $30(48.4)$ & 1.994 \\
\hline
\end{tabular}

$\mathrm{P}=0.001 ; \mathrm{F}=18.905$

Table 3: Knowledge Score for each Centre.

Considering knowledge score above $50 \%$ as good and $<50 \%$ as poor, participants from Enugu had the worst knowledge score as 120 of 139 participants (88.4\%) had poor knowledge score. Participants from Zaria had the highest proportion of good knowledge score with $56.7 \%$
(38 of 67) of participants scoring above $50 \%$. $\mathrm{p}=0.001$; Phi and Cramer's V=0.352, $\mathrm{p}=0.001$ ).

Table 4 shows the response of participants on challenges facing the practice of BMT in Nigeria. About 54 
participants $(12.2 \%)$ believed there was no challenge to BMT in Nigeria; $53(11.8 \%)$ participants believed the challenge was infrastructural only; 54 participants thought it was manpower only; 200 (45.4\%) participants believed the challenges included both infrastructure and manpower. Comparing the response of participants across centres, a good number of participants from Maiduguri $(60.4 \%)$ and Zaria $(53.2 \%)$ believed both infrastructure and manpower were challenges to the successful take-off of BMT service in Nigeria.

\begin{tabular}{|c|c|c|c|c|c|c|c|}
\hline & Abuja & Enugu & Jos & Lagos & Maiduguri & Zaria & Total \\
\hline None (\%) & $16(20)$ & $14(10.1)$ & $8(20)$ & $6(8.3)$ & $4(8.3)$ & $6(9.7)$ & $54(12.2)$ \\
\hline Infrastructure & $6(7.5)$ & $12(8.6)$ & $6(15)$ & $9(12.5)$ & $7(14.6)$ & $12(19.4)$ & $52(11.8)$ \\
\hline Manpower & $10(12.5)$ & $42(30.2)$ & $10(25)$ & $20(27.8)$ & $5(10.4)$ & $7(11.3)$ & $94(21.3)$ \\
\hline Both & $39(38.8)$ & $53(38.1)$ & $16(40)$ & $30(41.7)$ & $29(60.4)$ & $33(53.2)$ & $200(45.4)$ \\
\hline No response & $9(11.3)$ & $18(12.9)$ & $0(0)$ & $7(9.7)$ & $3(6.3)$ & $4(6.5)$ & $41(9.3)$ \\
\hline Total (\%) & $80(100)$ & $139(100)$ & $40(100)$ & $72(100)$ & $48(100)$ & $62(100)$ & $441(100)$ \\
\hline
\end{tabular}

Table 4: Challenges of BMT in Nigeria.

\section{Discussion}

In this study, the awareness of BMT by the participants was generally high (88.6\%). Though the awareness was generally high in all the participating centres, participants from Abuja expectedly had the highest level of awareness. This is probably because, Abuja is Nigeria's seat of power with many educated elites and media houses where information easily reaches the populace. We also found that in all centres, media and discussions with colleagues were identified as major sources of information. This shows the importance of peers and media in information dissemination. Access to information is very important in any society and is a veritable tool in the realization of individual, corporate and societal objectives or goals. It is now accepted as an important factor in the sustained development of any society because it reduces uncertainty, and enhances awareness of possible actions to take in solving problems [8]. Goldfrab A opined that information is a valuable resource required in any society; thus acquiring and using information are critical and important activities [9]. Therefore, information aimed at combating health menace such as sickle cell anaemia among many others is an important function of public health [10].

We found out that though awareness through other sources was generally low, the awareness created by schools was better than that of Journals, Seminars and Conferences. What could be responsible for this? Is it that Health care workers had little or no time for seminars and conferences? Was there paucity of organised forum for seminars and conferences on bone marrow transplantation? Is it that the purchasing power of health care workers is low such that little is left after spending on basic needs? Is it that the various centres were unable to sponsor workers for seminars and conferences due to the economic situation in the country? Do health care workers or organisations subscribe to journals? Are health workers no longer interested in publications in fields not core to their calling? All these are questions that need to be assessed.

All centres performed well when asked if their disciplines had a role to play in the practice of BMT. In this regard, Maiduguri centre had the highest score $(83.3 \%)$. When we combined the proportion of those who answered 'No; I don't know and 'No answer', Enugu centre with $54.6 \%$ of their participants had the highest proportion. This may indicate poor general knowledge of the procedure despite the high awareness level of the participants. This is further confirmed by the mean score of $38.4 \pm 2.06 \%$ on the test of knowledge on BMT when all participants were grouped together. This poor performance is recorded in all the centres. In fact, considering knowledge score $>50 \%$ as good scores and $<50 \%$ as poor, all centres had poor knowledge score. This shows that most health workers had inappropriate knowledge about BMT and continuous medical education on new innovations on health practices is desirable.

In varying proportions, many participants from all centres agreed that the major challenges to the practice of BMT in Nigeria include lack of manpower and infrastructure. This strongly supports the 2009 communiqué of the Nigerian national health conference which stated that health care system in Nigeria is weak as evidenced by lack of coordination, fragmentation of services, dearth of resources, inadequate and decaying infrastructure, inequity in resource distribution, and access to care and very deplorable quality of care [10] and that financial managerial competency, besides inadequate funding, remains a major problem in Nigeria [10]. 
In spite of the huge development in the health care in the last decades [11], much needs to be done in the health care system in Nigeria [12]. Health expenditure (\% of GDP) in Nigeria was 2.75 as of 2014. Its highest value over the past 19 years was 3.14 in 2003, while its lowest value was 1.81 in 2002 [13]. The health budget allocation for 2017 was a meagre 4.15 per cent, though a marginal improvement on the 3.73 per cent figure of 2016 [14] This is grossly inadequate and explains why various statistics show that Nigeria has one of the worst health records in the world [15]. Our health sector has been bedevilled by a myriad of challenges that resulted from lack of planning, policy disconnections, inadequate capital spending, poor remuneration, outdated technologies, poor infrastructure, sharp disparities in the availability of medical facilities across the country, coupled with the severe political and economic stresses of the past years. If the management of any health care system is to be successful, it should be directed through a set of policies and plans adopted by the government, private sector and other interest groups.

\section{Conclusion}

Though the awareness was high amongst health workers, majority of them had inappropriate knowledge of BMT; hence the desirability for continuous medical education on new innovations and advances in the health sector particularly in haematopoietic stem cell transplantation.

\section{Limitation of this Study}

The population studied in this work is heterogeneous (Haematologists, Medical Microbiologists, Immunologists, Clinical Pathologists, Anaesthesiologists, Nurses, Pharmacists, Clinical Psychologists, Laboratory Scientists/Technicians, Dieticians, Radiologists/Radiographers, and Social Health Workers/Health Counsellors). We therefore recommend that larger studies should be carried out in homogenous populations of health professionals.

Disclosure: The authors report no conflicts of interest in this work.

\section{References}

1. Hardy RE, Ikpeazu EV (1989) Bone marrow transplantation: a review. J Natl Med Assoc 81(5): 518-523.
2. Kasakura S (2005) Great contributions of E. Donnall Thomas to the development of clinical applications of bone marrow transplantation, leading to the 1990 Nobel Prize in Medicine/Physiology. Int J Hematol 81(2): 87-88.

3. Armitage JO (1994) Bone marrow transplantation. $\mathrm{N}$ Engl J Med 330(12): 827-838.

4. Devine SM, Lazarus HM, Emerson SG (2003) Clinical application of hematopoietic progenitor cell expansion: current status and future prospects. Bone Marrow Transplantation 31(4): 241-252.

5. Worldometers: Nigeria population (Live) http://www.worldometers.info/worldpopulation/nigeria-population/ Accessed 10th September, 2018.

6. Galadanci N, Wudil BJ, Balogun TM, Ogunrinde GO, Akinsulie A, et al. (2014) Current sickle cell disease management practices in Nigeria. Int Health 6(1): 2328.

7. Bazuaye $\mathrm{N}$, Nwogoh B, Ikponmwen D, Irowa $\mathrm{O}$, Okugbo S, et al. (2014) First successful allogeneic hematopoietic stem cell transplantation for a sickle cell disease patient in a low resource country (Nigeria): a case report. Ann Transplant 19: 210-213.

8. Familusi EB, Owoeye PO (2014) An assessment of the use of radio and other means of information dissemination by the residents of Ado- Ekiti, EkitiState, Nigeria. Library Philosophy and Practice (ejournal) 1088: 1-29.

9. Goldfarb A (2006) The teaching role of Universities in the diffusion of the internet. International Journal of Industrial Organization 24(2): 203-225.

10. Welcome MO (2011) The Nigerian health care system: Need for integrating adequate medical intelligence and surveillance systems. J Pharm Bioallied Sci 3(4): 470-478.

11. Awosika L (2005) Health insurance and managed care in Nigeria. Ann Ibadan Postgrad Med 3: 40-46.

12. Adeyemo DO (2005) Local government and health care delivery in Nigeria: A Case Study. J Hum Ecol 18(2): 149-160.

13. https://www.indexmundi.com/facts/nigeria/healthexpenditure 


\section{Haematology International Journal}

14. https://guardian.ng/opinion/health-budget-for2017-is-poor

15. Onyeji E (2018) Budget: Again, Nigeria falls short of AU health funding commitment. Premium Times. https://www.premiumtimesng.com/news/headlines /248909-2018-budget-nigeria-falls-short-au-healthfunding-commitment.html Accessed 10th September, 2018. 